\title{
Study on the influence of cell opening on traffic condition based on circuit analogy theory
}

\author{
Bin yang \\ ${ }^{1}$ School of North China Electric Power University, Baoding 071000, China \\ 544635057@qq.com
}

\begin{abstract}
This paper mainly studies the influence of the closed area open to the surrounding city road traffic, a traffic impact area road network evaluation system and analog system analysis model, using the method of circuit simulation system was solved by the analysis of the traffic network. The closed area traffic will open to some extent alleviate the city traffic congestion, but also for the city main road traffic sharing traffic pressure ${ }^{[1]}$. Through simulating circuit system using the analytical method, network theory, study network traffic flow characteristics, traffic flow model ${ }^{[3]}$. analog circuit theory used in network traffic flow is a part of the study, the basic theory of analog circuit system and traffic network equilibrium theory construction area and the surrounding road network traffic flow model based on the research, thus affect the community open to the surrounding road traffic.
\end{abstract}

Keywords: District open, traffic impact degree, circuit simulation model.

\section{Introduction}

Residential traffic impact evaluation index should be able to fully reflect the area before and after the opening of its surrounding local network operation status. The effects should be considered in their own areas of each factor and the surrounding road network performance. In this paper, the concept of traffic impact of the definition, the comprehensive evaluation index as a small influence on the surrounding road network traffic.

In this paper, the concept of traffic impact of the definition, the comprehensive evaluation index as a small influence on the surrounding road network traffic.In this paper, the residential traffic impact degree can be considered to consist of two factors, namely the week side network indicators and their own areas. In the process of determining index analysis the influence factors of the surrounding road network, this paper has studied ${ }^{[2]}$, selection of road saturation and intersection saturation degree as the evaluation index. Therefore, the surrounding road network is necessary here the first study area at the entrance of cross traffic.

\section{Evaluating indicator}

Through access to relevant information and analysis, this paper summarizes the significant factors, 8 of the traffic impact were: road rush hour C1 cross peak hour saturation, saturation C2, local area network reliability $\mathrm{C} 3$, local area road network vulnerability $\mathrm{C} 4$, residential entrance connection $\mathrm{C} 5$, exit channel C6 residential, residential location index C7, covers an area of C8.

\section{Constructing evaluation index system based on Analytic Hierarchy Process}

When determining the traffic impact evaluation system of machine specific research index relationship, we need to further qualitatively and quantitatively determine the weight of each index. This paper uses AHP to determine the weights of these indexes. 


\subsection{Building structural matrix}

The judgment matrix representation of hierarchical structure model, a layer of factors, the relative importance of the factors between all levels, determined by the 22 method of comparison, judgment matrix was constructed as follows.Aij judgment matrix elements of $\mathrm{A}$, it shows that $\mathrm{AI}$ is important relative to the level of AJ.Aij table definition definition and description of $1 \sim 9$ the AHP scaling law.

\subsection{Weight analysis}

A matrix for solving the eigenvalue equation, I for the unit matrix, the eigenvalue of $I(i=1,2), \ldots$ (n), the maximum eigenvalue is lambda max, corresponding to lambda max of the standard feature vector is $\mathrm{Y}=(\mathrm{Y} 1, \mathrm{Y} 2), \ldots \mathrm{T}(\mathrm{yn}), \mathrm{Yi}(\mathrm{i}=1,2), \ldots$ (n) is the weight of the factor Ci to the target, and also is the relative importance of the eigenvector which corresponds to the maximum eigenvalue of the judgment matrix, which is the weightThe approximate solution of the maximum eigenvalue and eigenvector of the matrix:The $\mathrm{N}$ root mean square of the judgment matrix $\mathrm{A}$ :

$$
\bar{W}_{i}=\left(\prod_{j=1}^{n} a_{i j}\right)^{\frac{1}{n}}
$$

Normalization:

$$
W_{i}=\frac{\bar{W}_{i}}{\sum_{i=1}^{n} \bar{W}_{i}}
$$

Maximum eigenvalue:

$$
\lambda_{\max }=\sum_{i=1}^{n} \frac{(A \cdot W)_{i}}{n \cdot W_{i}}
$$

\subsection{Consistency check}

In view of the diversity of objective things in practice and the complexity of people understanding of the problem and one sidedness, unable to accurately determine the value of AIJ, can only roughly estimate. But the impact assessment results in order to prevent the consistency of the deviation is too large, we must check the consistency of judgement matrix.

Consistency index CI: $\quad C I=\left(\lambda \_\max -n\right) /(n-1)$

Average random consistency index RI:

Table.1 Numerical value of RI

\begin{tabular}{ccccccccc}
\hline Dimension & 3 & 4 & 5 & 6 & 7 & 8 & 9 & 10 \\
\hline RI & 0.58 & 0.90 & 1.12 & 1.24 & 1.32 & 1.41 & 1.45 & 1.49 \\
\hline
\end{tabular}

The relative consistency index CR: $\quad C R=\frac{C I}{R I}$

By using the above analysis steps, the weights of the criteria and measures are determined, and the corresponding weights of the traffic impact assessment indexes of the residential areas are determined by the analytic hierarchy process (AHP):

Table.2 Weight of each index

\begin{tabular}{cc}
\hline Index & Weight \\
\hline Peak hour saturation & 0.0341236 \\
Peak hour saturation & 0.1420264 \\
Local road network reliability & 0.0767780 \\
Local road network vulnerability & 0.0255927 \\
Community entrance connection & 0.3408633 \\
Residential entrance channelization & 0.0852158 \\
Position & 0.1970320 \\
The measure of area & 0.0983683
\end{tabular}




\section{Evaluation grade}

According to the study of the residential area, through the calculation of the hierarchical weight, the traffic impact degree score is obtained. According to the data provided by the data [2], the impact of open traffic is divided into the following four levels:

Table.3 Classification of traffic impact degree

\begin{tabular}{ccc}
\hline Level & $\begin{array}{c}\text { Numerical } \\
\text { classification }\end{array}$ & Describe \\
\hline I & $>0.7$ & The impact of the road network, to a large extent will cause \\
traffic jams
\end{tabular}

\section{Practical case calculation and evaluation}

In this paper, a closed area is selected as the research object, the geographical map, road map and circuit simulation diagram of the area are as follows:

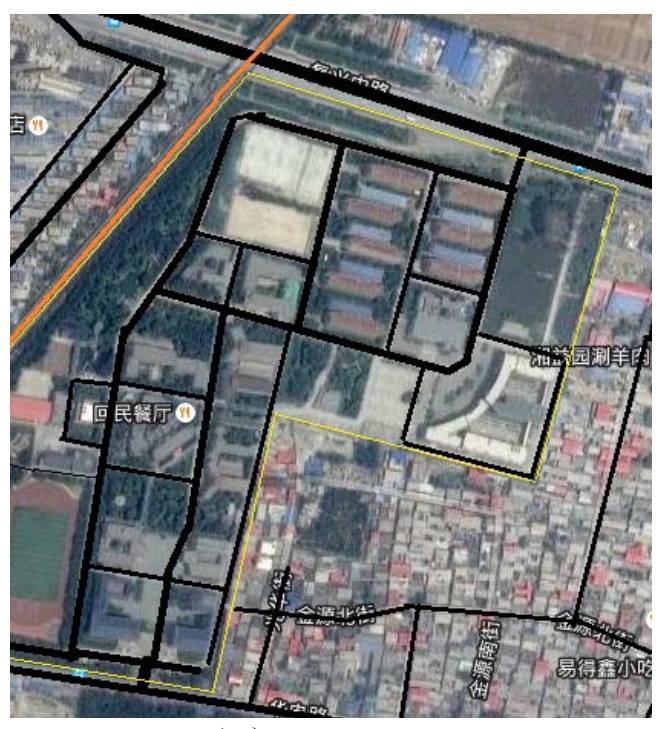

(a) Case aerial map

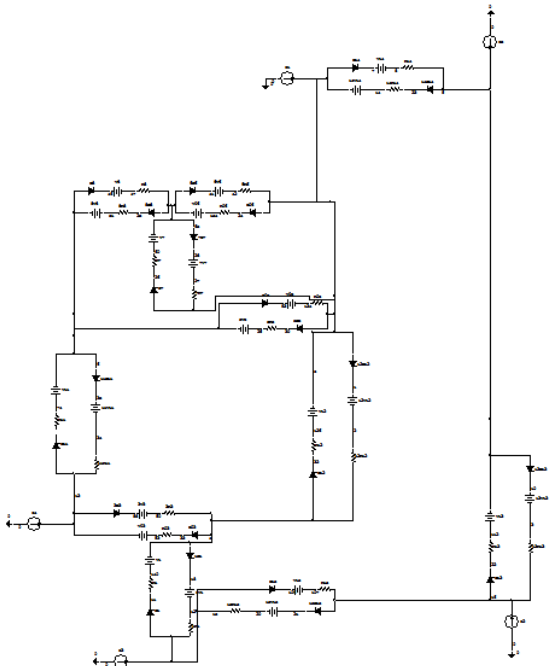

(b) Analog circuit simulation model

Table.4 Calculation of each index

\begin{tabular}{ccc}
\hline index & $\begin{array}{c}\text { Original } \\
\text { values }\end{array}$ & $\begin{array}{c}\text { Subsequent } \\
\text { values }\end{array}$ \\
\hline $\begin{array}{c}\text { Peak hour saturation } \\
\text { Intersection peak hour } \\
\text { saturation }\end{array}$ & 0.8 & 0.85 \\
$\begin{array}{c}\text { Local road network reliability } \\
\text { Local road network } \\
\text { vulnerability }\end{array}$ & 0.86 & 0.78 \\
$\begin{array}{c}\text { Community entrance } \\
\text { connection }\end{array}$ & 0.84 & 0.89 \\
$\begin{array}{c}\text { Residential entrance } \\
\text { channelization }\end{array}$ & 0.6 & 0.72 \\
$\quad$ position & $2.5 / 4$ & $2 / 4$ \\
The measure of area & $3 / 4$ & $2.5 / 4$ \\
Traffic impact degree & 0.36 & 0.36 \\
\end{tabular}




\section{References}

[1] Li Xiangpeng. Urban traffic congestion countermeasure research on traffic opening of closed community [D]. Changsha University of Science and Technology, 2014

[2] Shang Zhong Hua. Research on traffic impact analysis of residential area development [D]. Chang'an University, 2006

[3] Zhao Zhihong. Research on network traffic flow model structure of analog circuit system [D]. Jilin University, 2002

[4] Zhang Haixia. Research on urban traffic network equilibrium analysis based on circuit theory [D]. Jilin University, 2004

[5] Dong Jing, Zhang Zuo. Braess paradox in non cooperative transportation network and its avoidance of [J]. highway traffic technology, 2004,05:92-95. 